\title{
Life cycle assessment of solar-driven oxidation as a polishing step of secondary-treated urban effluents
}

\author{
Lida loannou-Ttofa, ${ }^{\text {a }}$ Spyros Foteinis, ${ }^{a}$ Efthalia Chatzisymeon, ${ }^{b}$ \\ Irene Michael-Kordatou ${ }^{\mathrm{a}}$ and Despo Fatta-Kassinos ${ }^{\mathrm{a}, \mathrm{c}^{*}}$
}

\begin{abstract}
BACKGROUND: In this work, the life cycle assessment (LCA) methodology is utilized to estimate the environmental footprint of solar Fenton oxidation at pilot scale used as a polishing step of secondary-treated urban effluents. All inputs (e.g. natural resources, raw materials, etc.) and outputs (e.g. emissions, etc.) of the process were quantitatively defined and/or estimated. The system under study includes raw materials, energy, land use, chemicals, local transportation needs, and air-/waterborne emissions.

RESULTS: The main environmental hotspots of this system were identified (i.e. energy consumption and use of chemicals). The environmental sustainability of this technology was found to be high, since its environmental footprint for the treatment of 1 $\mathrm{m}^{3}$ of wastewater was found to be only $8.7 \mathrm{~kg} \mathrm{CO}_{2} \mathrm{~m}^{-3}$, which is approx. $1.6 \%$ of the total $\mathrm{CO}_{2}$ emissions of the treatment of the daily effluents of a Cypriot resident. Nevertheless, alternative scenarios were investigated, in order to further enhance its overall environmental performance.

CONCLUSIONS: The results indicate that the majority of the environmental impacts of this process could be attributed to indirect emissions, tracing back to electricity generation, followed by emissions from the chemicals used. The most critical improvement identified herein, is the use of a renewable energy source.

(C) 2016 Society of Chemical Industry
\end{abstract}

Keywords: impact assessment; life cycle analysis; sensitivity analysis; solar Fenton oxidation; urban wastewater

\section{INTRODUCTION}

Nowadays, wastewater reclamation is one of the tools available to better manage water resources. Although wastewater reuse is widely accepted as one of the main solutions for water scarcity, a number of wastewater 'quality' challenges are associated with this practice, while there are only a few countries where reuse is extensively implemented. The occurrence of various contaminants of emerging concern (CECs), including among others pharmaceuticals (e.g. antibiotics, analgesics, antipyretics, etc.) and personal care products (e.g. parabens, etc.) in conventionally-treated wastewater effluents and receiving water bodies is nowadays a critical issue. ${ }^{1-4}$ Pharmaceuticals removal, for example, during conventional activated sludge (CAS) treatment ranges from almost zero to high biodegradation, depending on the type of microcontaminant and its biodegradability, but it is far from complete biodegradation. ${ }^{5-7}$ As a consequence, effective tertiary and/or advanced treatment technologies (e.g. advanced chemical oxidation processes (AOPs), UV disinfection, etc.) used as post-treatment of conventional biological systems are required.

It is important to underline that recently, three macrolide antibiotics widely used in human medicine (i.e. erythromycin, clarithromycin and azithromycin) have been introduced into the special 'watch list' of substances known to potentially pose environmental implications for the aquatic environment for European Union-wide monitoring in the field of water policy pursuant to Directive 2008/105/EC of the European Parliament and of the Council (EU, 2015/495). ${ }^{8}$ This highlights further the need for developing and applying alternative wastewater treatment technologies, which will efficiently remove such contaminants from the effluents. According to various studies, AOPs were found to be capable of completely removing various pharmaceutical compounds, such as sulfamethoxazole, carbamazepine, diclofenac, atenolol, propranolol, 17a-ethinylestradiol, ibuprofen, paracetamol, ofloxacin, erythromycin, cocaine, etc. ${ }^{9-14}$

\footnotetext{
Correspondence to: D Fatta-Kassinos, Nireas-International Water Research Center, University of Cyprus, P.O. Box 20537, CY-1678, Nicosia, Cyprus. Email:dfatta@ucy.ac.cy

a Nireas-International Water Research Center, University of Cyprus, P.O. Box 20537, CY-1678, Nicosia, Cyprus

b Institute for Infrastructure and Environment, School of Engineering, University of Edinburgh, Edinburgh EH9 3JL, UK

c Department of Civil and Environmental Engineering, School of Engineering, University of Cyprus, P.O. Box 20537, CY-1678, Nicosia, Cyprus
} 
When tertiary treatment is applied after the secondary step, the wastewater treatment's energy consumption increases, varying from very low for simple chlorination to high levels of energy consumption, when the treatment involves costly processes, such as ultraviolet disinfection, AOPs, and/or reverse osmosis. ${ }^{15-17}$ However, there are several AOPs that can be performed under solar irradiation (i.e. homogeneous and heterogeneous photocatalysis), which is a renewable and clean energy source, minimizing thus their environmental impacts related to the energy usage.

Life cycle assessment (LCA) is a methodological framework for estimating and assessing the environmental impacts attributable to the life cycle of a product or a process. ${ }^{16}$ In recent years, LCA analysis has gained popularity as an assessment tool for environmental sustainability of various wastewater treatment processes. ${ }^{18}$ In the LCAs conducted to date, focused on wastewater treatment and reuse, AOPs have not been rated as the most environmentally friendly technologies, mainly due to their high electricity consumption. ${ }^{19-22}$ However, since there is a need for removing persistent and toxic compounds from wastewater, such as various CECs, the application of an advanced technology as post-treatment potentially accompanied by higher environmental impacts, but concurrently able to efficiently remove these compounds, might be the best and maybe the only choice. The reason is that bio-persistent and toxic compounds existing in wastewater effluents, may induce adverse effects in ecosystems, when released into the environment. Nonetheless, until now the environmental footprint of the advanced chemical technologies, especially at pilot scale, applied for wastewater treatment remains largely unknown and thus this study tries to shed light and give a better insight on this aspect.

To the best of the authors' knowledge, LCA has been applied to AOPs in only a few cases. Specifically, in the study of Muñoz etal., a comparative environmental assessment of different bench-scale AOPs (i.e. $\mathrm{TiO}_{2}$ heterogenous photocatalysis (PhC), photo-Fenton (PhF), combined $\mathrm{TiO}_{2}$ heterogeneous photocatalysis and photo-Fenton (PhC-PhF), and $\mathrm{TiO}_{2}$ heterogeneous photocatalysis assisted with $\left.\mathrm{H}_{2} \mathrm{O}_{2}\left(\mathrm{PhC}+\mathrm{H}_{2} \mathrm{O}_{2}\right)\right)$ for the treatment of kraft mill bleaching wastewater at bench scale was performed. ${ }^{19}$ The results showed that the environmental impacts of all the studied AOPs were caused mainly by the amount of electricity consumed, whereas the impact of producing the chemical reagents and catalysts was comparatively low. As a consequence, the alternative scenario of using solar energy as a light source for these processes, was found to be able to reduce drastically the environmental impacts of all the AOPs tested (more than 90\%). The energy consumption was also found to be the main contributor of all the AOPs (i.e. $\mathrm{PhC}, \mathrm{PhC}+\mathrm{H}_{2} \mathrm{O}_{2}, \mathrm{PhC}-\mathrm{PhF}, \mathrm{PhF}$, ozonation $\left(\mathrm{O}_{3}\right)$ and ozonation with UV-A light irradiation $\left(\mathrm{O}_{3}+\mathrm{UV}-\mathrm{A}\right)$ ) investigated in a later study of Muñoz et al. ${ }^{20} \mathrm{~A}$ comparative LCA study of two solar-driven AOPs (i.e. solar PhC and solar PhF) at pilot scale, both coupled to biological treatment of a-methylphenylglycine in distilled water, was carried out by Muñoz et al. ${ }^{23}$ It was found that the overall environmental impacts of solar PhF were significantly lower than those of solar PhC (i.e. 80-90\%), mainly due to the larger size of solar collector field and the increased electricity needed in the latter case. In the study of Farré et al., an LCA study of two bench-scale AOPs (PhF and solar PhF) for the removal of herbicides from Mili-Q water was performed. ${ }^{24}$ When comparing these technologies from an environmental point of view, it was concluded that the PhF was the less preferable process. This process was greatly improved when artificial light was substituted by solar light, eliminating thus all the environmental impacts related to the electricity production. Moreover, in another study by Muñoz et al., different scenarios involving urban wastewater reuse (i.e. (i) wastewater discharge to a natural water stream after secondary treatment, (ii) wastewater reuse without tertiary treatment, (iii) wastewater reuse after tertiary ozonation treatment, and (iv) wastewater reuse after tertiary ozonation $+\mathrm{H}_{2} \mathrm{O}_{2}$ treatment) were examined. ${ }^{25}$ From an ecotoxicity perspective, wastewater reuse after applying ozonation and/or ozonation $+\mathrm{H}_{2} \mathrm{O}_{2}$ treatment appears to be the best option. Moreover, Meneses et al. applied an LCA to evaluate the environmental impacts of different disinfection processes (i.e. chlorination + UV treatment, ozonation, and ozonation $+\mathrm{H}_{2} \mathrm{O}_{2}$ ) for the treatment of urban wastewater at pilot scale. ${ }^{21}$ Chlorination + UV disinfection was found to have a lower impact than the two ozonation options in almost all environmental impact categories, mainly due to the lower energy consumption of the first process. On the other hand, the differences between the environmental impacts of single ozonation and ozonation $+\mathrm{H}_{2} \mathrm{O}_{2}$ were minimal. In addition, a comparative LCA of solar PhF and solar photoelectro-Fenton process, at bench scale, for the degradation of a-methylphenylglycine in distilled water, was performed by Serra et al. ${ }^{26}$ According to the results, the first process was found to be the most environmentally friendly, mainly due to the lower electricity demands compared with the latter. Moreover, LCA was used for estimating the impacts of three AOPs (i.e. UV/TiO ${ }_{2}$, wet air oxidation (WAO) and electrochemical oxidation (EO)) for the treatment of olive mill wastewater at bench scale. ${ }^{27}$ It was highlighted once again that the environmental sustainability of these processes is strongly related to their energy requirements, while their total environmental impacts decline in the following order: $\mathrm{UV} / \mathrm{TiO}_{2}>\mathrm{WAO}>\mathrm{EO}$. Giménez et al. focused on the environmental impact evaluation of two AOPs (PhC and PhF) in two different experimental setups: (i) solarbox (i.e. use of an artificial light source); and (ii) compound parabolic collectors (CPCs) (i.e. use of solar irradiation) at bench scale, for the removal of metoprolol from distilled water. ${ }^{27}$ According to the results, the highest environmental impacts were always associated with the energy consumption, either from the use of electric lamps, or from the energy requirements of the pumps, thermostats, stirrers, etc. PhC was found to be the less environmentally friendly process of the two processes examined, mainly due to the longer reaction time required. Finally, in a recent study by Rodriguez et al. LCA has been applied for the evaluation of both homogeneous and heterogeneous PhF processes at bench scale for the treatment of pharmaceutical wastewater effluents. ${ }^{28}$ The major environmental impact of the homogenous process was found to be the disposal of the metal ion-containing sludge generated during the treatment and not the energy consumption, as was the case in the majority of the above mentioned studies. In contrast, the heterogeneous system avoids the high impact derived from disposal of the solid waste, since lower concentration of catalyst was used; while the high dosage of $\mathrm{H}_{2} \mathrm{O}_{2}$ (almost four times higher than in the homogenous system) was found to be the main environmental hotspot of this process.

From all the above, it can be concluded that: (i) the main environmental contributors for almost all AOPs tested in the above studies were their high electricity consumption followed by the use of chemicals; and (ii) the solar Fenton oxidation was found to be one of the most environmentally friendly AOPs that could be successfully applied for the efficient treatment of various wastewater effluents.

It is important to underline that most of the above LCA studies of various AOPs ${ }^{19,20,22,25,28}$ have been carried out using bench-scale data, a fact that could potentially limit the usefulness of the 
outcomes with regard to real-scale applications. According to the authors' knowledge, this work constitutes one of the first integrated attempts to evaluate the environmental performance and impacts of solar Fenton oxidation at pilot scale, its main environmental hotspots, including also a sensitivity analysis and a life cycle improvement analysis, which are key elements, still missing from the existing scientific literature. In addition, it should be highlighted that in this study the optimum operational conditions of the solar Fenton process (i.e. chemicals dosages, treatment time, $\mathrm{pH}$, etc.) were extensively investigated and used, in order to achieve complete removal of the selected antibiotic compounds from secondary-treated effluents, and to significantly reduce both the organic load and the toxicity of the final effluent, in order for it to be safely used mainly for irrigation purposes.

\section{EXPERIMENTAL}

Considering that recently three antibiotic compounds were introduced into the special 'watch list' of substances known to potentially pose environmental impacts to the aquatic environment, according to the Directive 2008/105/EC (EU, 2015/495), as mentioned before, the investigation of the environmental impacts of various advanced chemical oxidation processes, capable of completely degrading these pharmaceutical compounds from conventionally-treated wastewater effluents is of high significance. ${ }^{8}$

Thus, in this study, solar Fenton oxidation at pilot scale was applied and investigated for: (i) the degradation of two antibiotic compounds (i.e. trimethoprim (TMP) and ofloxacin (OFX)) from secondary-treated effluents (e.g. the optimum operating conditions were investigated (e.g. reagent's concentrations, treatment time, $\mathrm{pH}$, etc.)); (ii) the assessment of their toxicity (prior to and after treatment) using a set of bio- and phyto-assays; and (iii) the assessment of the efficiency of the process to remove the antibiotic resistant enterococci.

\section{Description of the solar pilot plant}

The solar Fenton experiments were carried out in a CPC pilot plant, which consists of borosilicate glass tubes and is mounted on a fixed platform tilted at the local latitude $\left(35^{\circ}\right)$, operated in batch mode. The reflecting surface is constructed of resistant and highly reflecting aluminium. The urban wastewater flows directly from one tube to the other and finally to a reservoir tank in a meandering flow. A centrifugal pump returns the water to the collectors in a closed circuit. The overall capacity of the reactor, $V_{T}=250 \mathrm{~L}$, consists of the total irradiated volume, $V_{i}=85.4 \mathrm{~L}$ (tubes volume) and the dead reactor volume (i.e. tank, piping and valves). Storage tank, flow meters, $\mathrm{pH}$ sensor, air blower, control panel, pipes and fittings complete the installation. Furthermore, three reagent tanks along with their dosing pumps are installed in the solar pilot plant, which can automatically dose reagents (i.e. $\mathrm{H}_{2} \mathrm{SO}_{4}, \mathrm{H}_{2} \mathrm{O}_{2}$ and $\mathrm{FeSO}_{4} \cdot 7 \mathrm{H}_{2} \mathrm{O}$ ) directly to the storage tank. The experimental setup and procedure is described in detail in previous work of our group..$^{29,30}$

\section{Treatment efficiency of solar Fenton process}

It should be noted that $100 \mu \mathrm{g} \mathrm{L}^{-1}$ of each antibiotic examined herein (i.e. OFX and TMP) was used as initial concentration, which is a compromise between: (i) a sufficiently high concentration to characterize the degradation kinetics using available analytical techniques; and (ii) a low enough concentration to simulate real environmental conditions (considering that the concentrations of antibiotics are in the $n g-\mu \mathrm{g} \mathrm{L}^{-1}$ range in secondary-treated effluents). ${ }^{29}$

Preliminary solar Fenton experiments were carried out using 5 $\mathrm{mg} \mathrm{L}^{-1}$ of Fe${ }^{2+}$ at several $\mathrm{H}_{2} \mathrm{O}_{2}$ doses (between 25 and $100 \mathrm{mg} \mathrm{L}^{-1}$ ) to establish the best $\mathrm{H}_{2} \mathrm{O}_{2}$ dose for the antibiotics removal (data presented in detail in previous work). ${ }^{29}$ Solar Fenton oxidation under optimum experimental conditions (i.e. $5 \mathrm{mg} \mathrm{L}^{-1} \mathrm{Fe}^{2+}$ and $75 \mathrm{mg} \mathrm{L}^{-1} \mathrm{H}_{2} \mathrm{O}_{2}$ ) was able to achieve complete removal of OFX and TMP (initial concentration of $100 \mu \mathrm{g} \mathrm{L}^{-1}$ ) within $180 \mathrm{~min}$ of solar treatment, as well as COD and DOC removal of $50 \%$ and $21 \%$, respectively. In addition, the solar Fenton process was found able to significantly reduce the initial wastewater toxicity against: (i) three examined plant species (i.e. Sorghum saccharatum, Lepidium sativum and Sinapis alba) after $180 \mathrm{~min}$ of treatment (i.e. up to $60 \%$ reduction of root inhibition and up to $30 \%$ reduction of shoot inhibition); and (ii) the water organism Daphnia magna (i.e. after $300 \mathrm{~min}$ of treatment the daphnids immobilization was decreased to $6.7 \%$ at $48 \mathrm{~h}$ exposure).

Moreover, solar Fenton oxidation contributed significantly to the prevalence of enterococci bacteria (often used as indicators of the microbial quality of waters), including those resistant to TMP and/or OFX, in the treated samples, achieving thus complete removal of resistant enterococci. More specifically, the average enterococci population in the initial wastewater sample was $2.53 \times 10^{3}$, whereas the bacteria population was completely eliminated at the end of the treatment (i.e. $180 \mathrm{~min}$ ) under the optimum operating conditions.

Finally, it should be highlighted that the treatment process resulted in an effluent stream that fulfills the quality criteria of the Cypriot legislation (Cyprus Regulatory Administrative Act 772/2003) (i.e. COD: 125 mg L-1; TSS: $35 \mathrm{mg} \mathrm{L}^{-1}$; TN: $15 \mathrm{mg} \mathrm{L}^{-1}$; TP: $2 \mathrm{mg} \mathrm{L}^{-1}$ ), in order to be safely reused for irrigation purposes or to be discharged into surface waters, where water is used only for irrigation and not for potable use. ${ }^{31}$

\section{METHODOLOGY OF LCA}

\section{Goal and scope definition}

The main objective of this study was to examine and assess the environmental sustainability of solar Fenton oxidation at pilot scale, used as a polishing step of secondary-treated urban wastewater containing selected antibiotic compounds (i.e. OFX and TMP). The environmental impacts of this process were evaluated by considering all flows from and to nature and technosphere, its waterborne and airborne emissions, as well as its energy consumption. Its environmental footprint was assessed by a single and a multi-issue environmental impact assessment method, i.e. IPCC 2013 (version 1.00) and ReCiPe (version 1.10), respectively. The first was employed to better communicate results to non-academic audiences, while the second one, to identify the impact categories (midpoint) and the areas of protection (endpoint) that are affected by the construction and operation of this process.

\section{Functional unit}

The functional unit chosen for this LCA study is 'the treatment of 1 $\mathrm{m}^{3}$ of secondary-treated urban wastewater, completely removing OFX and TMP and sufficiently reducing its organic load and toxicity, achieving thus an effluent quality that allows safe discharge into the environment'. In addition, it is estimated that the useful lifetime (life span) of the system is 20 years, which is in line with the advice obtained by the Cypriot manufacturer of the system. 


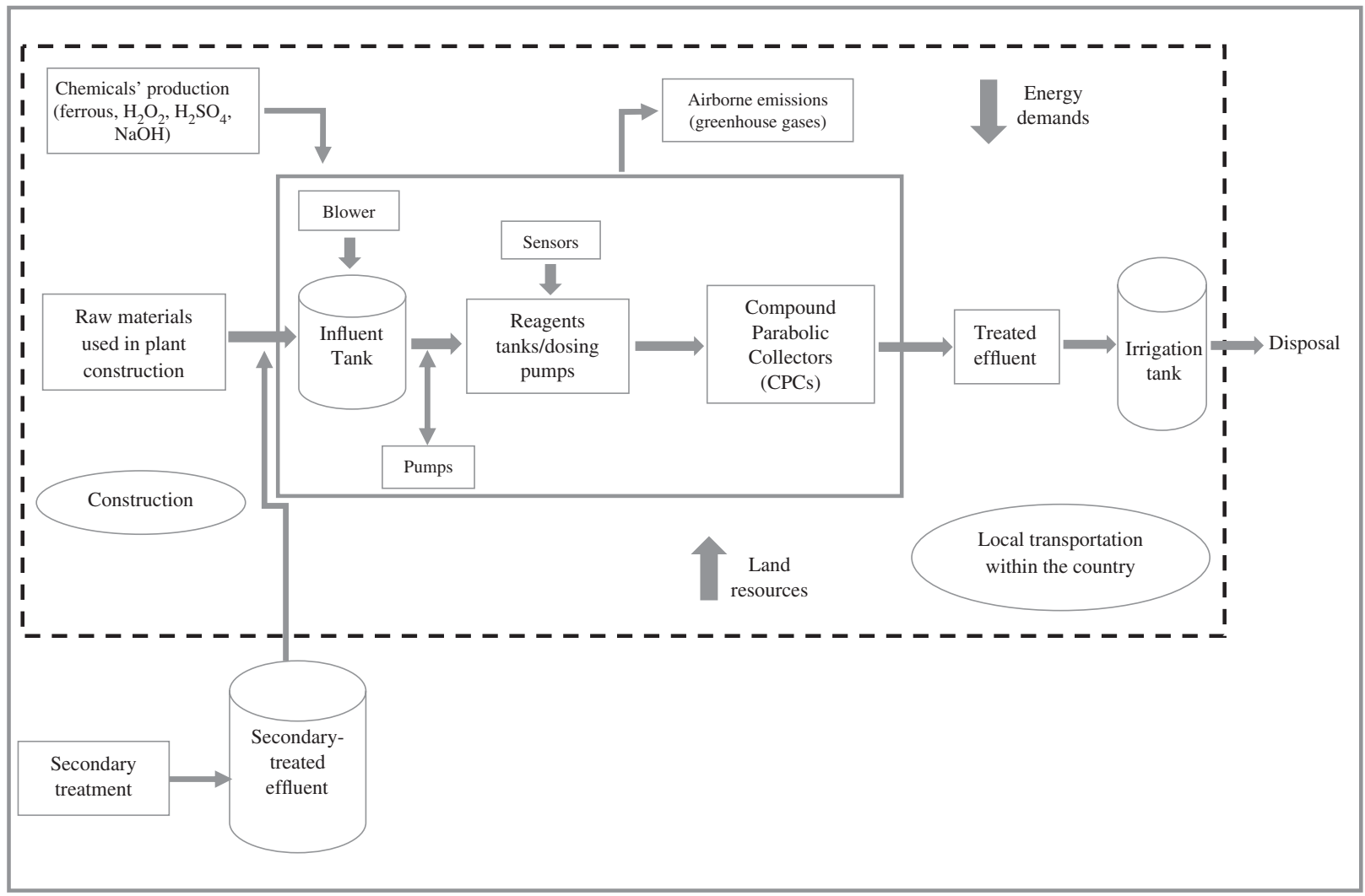

Figure 1. System boundaries of the LCA study.

\section{System boundaries}

As shown in Fig. 1, the system boundaries (dotted lines in Fig. 1) include the materials used for the construction of the pilot plant, the land use, the operational equipment, the energy usage of all components, and other system outputs to the environment, such as airborne emissions and the treated effluent, as to its qualitative and quantitative physicochemical characteristics. In addition, the transportation for the construction and maintenance of the unit, within the country, was also included in the system boundaries. On the other hand, the biological pre-treatment was not included in the system boundaries, since this pre-treatment step was beyond the scope of this study. Moreover, the recycling of the unit's main materials (e.g. stainless steel, plastics, etc.) was included in the LCA analysis, while the non-recycled parts (e.g. flowmeter, electronics for control panel, UV meter, etc.) were assumed to be buried at a sanitary landfill. Finally, the discharge of the treated effluents into the environment was not considered within the scope of the study and hence, was not included in the system boundaries. This was because in this study a cradle-to-gate approach was used, and as a consequence the final disposal or reuse of the treated effluents were external to the system boundaries. The reason is that the route of the effluents' disposal can significantly affect the overall sustainability of the process and therefore its inclusion would make results valid only for the specific route, which was not desirable in the present case study.

\section{Assumptions}

The main assumptions taken into account were the following:

- The solar pilot plant was operated in batch mode (the treatment capacity is equal to $0.25 \mathrm{~m}^{3}$ for each experiment, which lasts $3 \mathrm{~h}$ ) for $10 \mathrm{~h} \mathrm{day}^{-1}$, all year round (i.e. 365 days per year), translating into $0.833 \mathrm{~m}^{3}$ of urban wastewater being treated daily.

- Solar Fenton experiments were performed using $\mathrm{Fe}_{2} \mathrm{SO}_{4} \cdot 7 \mathrm{H}_{2} \mathrm{O}$ as the Fe(II) source. Nonetheless, it was not possible to identify this chemical reagent in SimaPro databases or in the available scientific literature. Thus, $\mathrm{Fe}_{2}\left(\mathrm{SO}_{4}\right)_{3},{ }^{32}$ which is an iron-based catalyst similar to $\mathrm{Fe}_{2} \mathrm{SO}_{4} \cdot 7 \mathrm{H}_{2} \mathrm{O}$, was used instead.

- For the local transportation of the equipment needed for the construction and maintenance of the unit, as well as the chemicals used, a mean distance of $80 \mathrm{~km}$ was assumed, which was the distance from the city where the pilot plant was constructed to the city where it was installed, using a truck (approx. 7.5 tonnes) and a van (light vehicle, $<2.5$ tonnes), respectively.

- The useful lifetime of the unit was assumed to be 20 years, according to the suggestion of the manufacturer.

- The borosilicate glasses used in the CPCs of the pilot plant have a life of about five years, according to the manufacturer, and thus it was assumed that the collectors are to be replaced four times during the lifetime of the plant (i.e. 20 years). It should be noted that this pilot plant is in operation for seven years at the premises of the University of Cyprus, in Nicosia, Cyprus. In the fifth year of operation the borosilicate tubes were replaced with new ones, due to damage (i.e. cracks) sustained from the local climatic conditions (i.e. high temperature difference between day and night (more than $\left.10-15^{\circ} \mathrm{C}\right)$ ).

- The motor that was chosen to be used for the construction of the air blower and the pumps under study has a lifetime of 15 years, according to the available scientific literature. ${ }^{33}$

- It was assumed that the pipes (UPVC PE) have a lifetime of at least 50 years, according to Sand; ${ }^{34}$ thus no replacement during the lifetime of the unit was needed. 
Table 1. LCl data of the solar pilot plant under study

Storage tank (stainless steel, $\mathrm{Fe} / \mathrm{Cr}_{18} / \mathrm{Ni}_{10}$ )

Feed pump (stainless steel and carbon/ceramic/NBR)

Transfer pump (stainless steel, $\mathrm{Fe} / \mathrm{Cr}_{18} / \mathrm{Ni}_{10}$ )

Air blower (aluminum alloy)

Three solution tanks (polyethylene)

Three dosing pumps (stainless steel, $\mathrm{Fe} / \mathrm{Cr}_{18} / \mathrm{Ni}_{10}$ )

Sensor (transparent PVC)

24 compounds parabolic collectors (borosilicate glass)

UV meter (stainless steel, $\mathrm{Fe} / \mathrm{Cr}_{18} / \mathrm{Ni}_{10}$, silicon carbide based photodiode teflon diffuser)

Two flowmeters (polypropylene)

Pipes (UPVC PE)

Catalyst $\left(\mathrm{FeSO}_{4}\right)\left(5 \mathrm{mg} \mathrm{L}^{-1}\right)$

Oxidant $\left(\mathrm{H}_{2} \mathrm{O}_{2}\right)\left(75 \mathrm{mg} \mathrm{L}^{-1}\right)$

Sulfuric acid (pure) $\left(\mathrm{H}_{2} \mathrm{SO}_{4}\right)\left(2 \mathrm{~mol} \mathrm{~L}^{-1}\right)$

Sodium hydroxide (pure) $(\mathrm{NaOH})\left(2 \mathrm{~mol}^{-1}\right)$

\section{Operating parameters}

Treatment time

Wastewater treated volume per day

Removal efficiency

COD removal (\%)

DOC removal (\%)

OFX removal (\%)

TMP removal (\%)

\section{Energy requirements}

Energy from the national grid (medium voltage)

$\mathrm{kWh}$ for the treatment of $1 \mathrm{~m}^{3}$ of urban wastewater

Airborne emissions (data provided from Muñoz et al. ${ }^{23}$ )

$\mathrm{CO}_{2}$

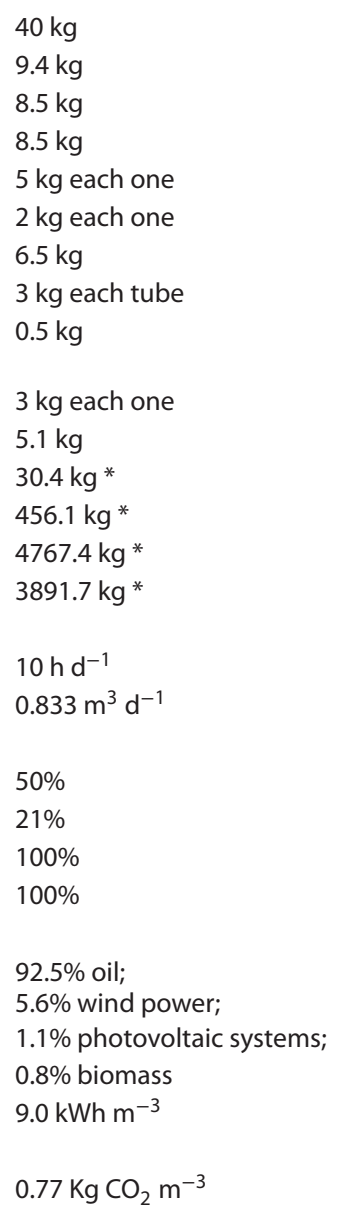

*The quantities of reagents used were calculated for the whole lifetime of the solar pilot plant (i.e. $20 \mathrm{yr}$ ).

- Extraordinary conditions (i.e. flooding of the plant, unexpected stoppage of the units, etc.) were excluded from the LCA study (i.e. considered to be outside of the system boundaries).

- The construction, operation and maintenance data (e.g. pieces of equipment of the plant, construction materials, manufacturing processes, etc.) have been taken from the Cypriot manufacturing company.

- The data regarding airborne emissions of the operation of the unit were obtained from the available scientific literature. ${ }^{23}$

\section{Life cycle inventory analysis}

Life cycle inventory ( $\mathrm{LCl}$ ) analysis is the process of quantifying energy and raw material requirements, atmospheric and waterborne emissions, as well as solid wastes released during the entire life cycle of a product, process, or activity. ${ }^{35}$ In this study, an attributional LCA was used, which aims to describe the environmentally relevant physical flows to and from a life cycle and its subsystems.

Table 1 summarizes the inventory data, highlighting the amount of materials needed to manufacture the solar pilot plant, as well as the electricity and chemicals consumed during its lifetime. Data on materials and energy consumption, as well as characterization of the wastewater entering and leaving the facilities were collected from on-site experiments and lab analysis that were carried out, as well as from the Cypriot manufacturer of the unit. Regarding airborne emissions, only the $\mathrm{CO}_{2}$ emissions were taken into account in this LCA study, according to the study of Muñoz et al., as shown in Table $1 .{ }^{23}$ The Ecoinvent 3.01 database was selected as the preferred option to be used for the LCl. Moreover, the Cypriot electricity mix and the equipment presented below were created from literature data, due to their absence from the existing SimaPro's LCl databases.

The electricity mix of Cyprus consists of $92.5 \%$ from oil, $5.6 \%$ from wind power, $1.1 \%$ from photovoltaic systems and $0.8 \%$ from biomass. ${ }^{36}$ Data from SimaPro's LCl databases were used to model it.

The types of the pumps and the air blower used for the operation of the specific unit were not available in the existing databases. For this reason, a literature search was conducted, and the available $\mathrm{LCl}$ data identified were related to the main part of this equipment, i.e. their motor. More specifically, relevant $\mathrm{LCl}$ data were identified in $\mathrm{ABB}$ Motors $\mathrm{A} / \mathrm{S}^{33}$ containing $\mathrm{LCl}$ data for motors with output of $1.1 \mathrm{~kW}$ (ABB Motor Type 90s). ${ }^{37,38}$ Therefore, the data for this motor were re-scaled to fit the rated output of the motor of the blower (i.e. $84 \mathrm{~W}$ ), of the feed pump (i.e. $0.37 \mathrm{~kW}$ ) and of the $\mathrm{H}_{2} \mathrm{O}_{2}, \mathrm{FeSO}_{4}$ and $\mathrm{H}_{2} \mathrm{SO}_{4}$ dosing pumps (i.e. $50 \mathrm{~W}$ ) under study. The life span of this motor is 15 years, when operating $5000 \mathrm{~h}$ per 

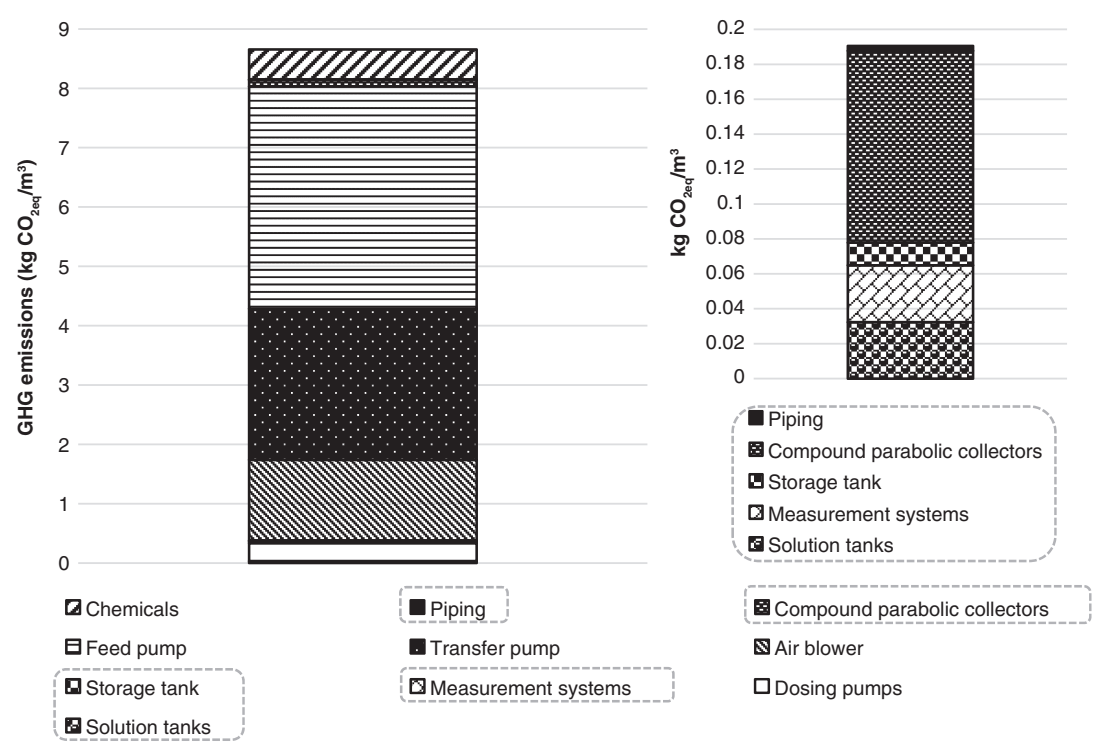

Figure 2. GHG emissions of each parameter of the system for the treatment of $1 \mathrm{~m}^{3}$ of urban wastewater using the IPCC $2013 \mathrm{impact}$ assessment method.

year. Regarding the transfer submersible pump (0.25 kW), relevant $\mathrm{LCl}$ data were identified in the environmental product declaration (EPD) of the Grindex MINEX 8101.171 submersible pump, ${ }^{39}$ which were re-scaled and used in this study. The life span of the pump was considered to be 5 years, with an assumed operation time of 2200 hours per year.

\section{Life cycle impact assessment}

After the compilation, tabulation and preliminary analysis of all environmental exchanges, a process known as $\mathrm{LCl}$, it is often necessary for practitioners to calculate, as well as to interpret indicators of the potential impacts associated with such exchanges with the natural environment (life cycle impact assessment, LCIA).$^{16}$ In this stage, the LCl data collected were assessed with SimaPro 8.0.3.14.

Two impact assessment methods were used in this case study, namely IPCC 2013 version 1.00 and ReCiPe version 1.10. The first impact assessment method compares processes based on $\mathrm{CO}_{2}$ emissions equivalent $\left(\mathrm{CO}_{2 \mathrm{eq}}\right)$, by measuring the global warming potential (GWP). The second assessment method comprises a broad set of 18 midpoint and three endpoint impact categories, including several environmental issues, in order to assess the product or process sustainability. These 18 midpoint impact categories are: 'climate change' (CC), 'ozone depletion' (OD), 'terrestrial acidification' (TA), 'freshwater eutrophication' (FE), 'marine eutrophication' (MEP), 'human toxicity' (HT), 'photochemical oxidant formation' (POF), 'particulate matter formation' (PMF), 'terrestrial ecotoxicity' (TET), 'freshwater ecotoxicity' (FET), 'marine ecotoxicity' (MET), 'ionising radiation' (IR), 'agricultural land occupation' (ALO), 'urban land occupation' (ULO), 'natural land transformation' (NLT), 'water depletion' (WD), 'metal depletion' (MD) and 'fossil depletion' (FD); while the three endpoint impact categories are 'human health', 'resources' and 'ecosystem'. It should be highlighted that this method is able to express the results per environmental impact category and also as an aggregated single score. ${ }^{40}$

\section{RESULTS AND DISCUSSION}

\section{LCIA results using the IPCC 2013 method}

First, the results were simulated by the impact assessment method IPCC 2013, with a timeframe of 100 years. The total GHG emissions of our process for the treatment of $1 \mathrm{~m}^{3}$ of secondary-treated urban wastewater were found to be $8.7 \mathrm{~kg}$ $\mathrm{CO}_{2 \mathrm{eq}} \mathrm{m}^{-3}$. The contribution of each parameter (e.g. pumps, tanks, air blower, chemicals, CPCs, etc.) of the unit to the total GHG emissions is presented in Fig. 2.

As shown in Fig. 2, the main contributor to the total environmental impacts of our process was the energy consumption of the pumps and the air blower, which accounted for $91.6 \%$ (i.e. $7.9 \mathrm{~kg} \mathrm{CO}_{2 \text { eq }} \mathrm{m}^{-3}$ ) of the total GHG emissions. The environmental impacts were mainly attributed to the specific energy mix used, which is heavily dependent on fossil fuels (i.e. oil) and accounted by itself for $90.2 \%$ (i.e. $7.8 \mathrm{~kg} \mathrm{CO}_{2 \mathrm{eq}} \mathrm{m}^{-3}$ ) of the total GHG emissions. This is in agreement with the study of Muñoz et al., where $93 \%$ of the $\mathrm{CO}_{2}$ emissions of the bench-scale photo-Fenton process were related to the electricity production and consumption. ${ }^{19}$ Moreover, $5.9 \%$ (i.e. $0.5 \mathrm{~kg} \mathrm{CO}_{2 \mathrm{eq}} \mathrm{m}^{-3}$ ) of the total $\mathrm{GHG}$ emissions was attributed to the use of chemicals for the oxidation process. More specifically, $3.6 \%$ of the GHG emissions was attributed to $\mathrm{NaOH}, 0.5 \%$ to $\mathrm{H}_{2} \mathrm{SO}_{4}$ and $0.7 \%$ to $\mathrm{H}_{2} \mathrm{O}_{2}$, while the transportation of the chemicals was found to be responsible for $1.1 \%$ of the total GHG emissions. It should be mentioned that sulfuric acid $\left(\mathrm{H}_{2} \mathrm{SO}_{4}\right)$ and sodium hydroxide $(\mathrm{NaOH})$ were used to adjust the $\mathrm{pH}$ of the treated effluents to 3.0 at the beginning of the solar Fenton process and to 7.0 at the end of the treatment, before its disposal in the environment. It is well known that during the Fenton process, the $\mathrm{pH}$ of the solution controls both the generation of hydroxyl radicals and the concentration of ferrous ions, and thus influences the oxidation efficiency. ${ }^{44}$ Thus, an acidic $\mathrm{pH}$ value equal to 3.0 was used as an optimum $\mathrm{pH}$ for the solar Fenton treatment, and as a result a further adjustment of the $\mathrm{pH}$ to neutral values was required before its disposal into the environment. It has to be noted that due to the non-toxic nature of $\mathrm{FeSO}_{4} \cdot 7 \mathrm{H}_{2} \mathrm{O}$ and the low amounts that were used for the solar Fenton oxidation of urban wastewater (i.e. $5 \mathrm{mg} \mathrm{L}^{-1}$ ), $\mathrm{FeSO}_{4} \cdot 7 \mathrm{H}_{2} \mathrm{O}$ had a minimal contribution to the total $\mathrm{CO}_{2}$ emissions of the system. This overall low environmental contribution of the chemical use is also in line with the results of the study by Muñoz et al., where the contribution of $\mathrm{H}_{2} \mathrm{O}_{2}$ and $\mathrm{FeCl}_{3}$ to the GWP of the photo-Fenton process was $4 \%$ and $0 \%$, respectively; while the impacts of transporting the chemicals were negligible. ${ }^{19}$ Moreover, according to the study by Farré et al., 
the environmental impact associated with $\mathrm{FeSO}_{4}$ was negligible, because as is mentioned, this chemical is a by-product of the steel and iron manufacturing industry and hence is charged with few environmental burdens. ${ }^{24}$ However, the foregoing findings do not coincide with those of the studies by Muñoz et al. and Serra et al., where the consumption of $\mathrm{H}_{2} \mathrm{O}_{2}$ was found to be a key factor in the environmental impacts of the photo-Fenton process. ${ }^{23,26}$ This is probably due to the different energy mixes used and the different assumptions on electricity usage of each study. It should be also highlighted that in this case study, solar Fenton oxidation was applied at pilot scale and not at bench scale, as was the case in the other studies mentioned above, and the electricity demand of the transfer and feed pumps, the air blower, as well as the three dosing pumps of the reagents was included and was a key factor of the total GHG emissions of the unit. In addition, the CPCs of the solar pilot plant contributed $1.1 \%$ to the total GHG emissions, with their main material, i.e. glass tubes, being responsible for most of it (i.e. $97.3 \%$ of their total environmental footprint). Finally, the use of all motors, contributed $0.6 \%$, with the transfer pump being responsible for most of it. It should be noted that this percentage refers to the environmental impact of the material production of the motors of the pumps and the air blower.

According to the European Environmental Agency, the average daily GHG emissions of a resident in Cyprus are $27.7 \mathrm{~kg} \mathrm{CO}_{\text {2eq }}$ (data for 2013) (EEA, Country profile - Cyprus, 2014), while its treated urban effluents are about $50 \mathrm{~L}_{\text {day }}{ }^{-1}$ (i.e. $16.65 \mathrm{~m}^{3}$ treated urban wastewater/people year in 2009). ${ }^{42,43}$ Therefore, according to the results of the IPPC 2013 method (i.e. total GHG emissions of our process equal to $8.7 \mathrm{~kg} \mathrm{CO}_{2 \mathrm{eq}} \mathrm{m}^{-3}$ ), the solar Fenton treatment of the average daily urban effluents of a Cypriot resident, would amount to about $1.6 \%$ of its daily total GHG emissions, highlighting thus the environmental sustainability of this advanced treatment technology. Considering that the solar Fenton oxidation could be applied as a post-treatment of a biological process, and according to the results of a previous LCA study of our team, where the biological treatment through a membrane bioreactor of the daily effluents of a Cypriot resident, was found to be $1.2 \%$ of its daily GHG emissions; the integrated treatment of these effluents (i.e. biological + solar Fenton) would amount to approx $3 \%$ of the total GHG emissions of a local resident. ${ }^{40}$ This is also an insignificant contribution to the overall daily $\mathrm{CO}_{2}$ emissions per person.

\section{LCIA results using ReCiPe V1.10 method}

The environmental impacts and damage of the process were estimated using the ReCiPe V1.10 impact assessment method. Results were expressed both at mid- and end-point level. ReCiPe utilizes three different perspectives, namely individualist, hierarchist and egalitarian, and in this case the default ReCiPe midpoint method was used, i.e. the hierarchist version.

Figure 3 shows the normalized midpoint impact categories of our system (European normalization and average weighting set). As shown, the majority of the environmental impacts were attributed to the electricity consumption, mainly by the pumps and the air blower, which is in line with the results of the IPPC 2013 method. Specifically, the feed pump, the transfer pump and the air blower have the highest contribution, from higher to lower, in most environmental impact categories, due to the electricity consumption. In general, the operation of the pumps mainly contributed to the midpoint impact categories 'natural land transformation', 'marine ecotoxicity', 'freshwater ecotoxicity', 'human toxicity', 'terrestrial acidification' and 'fossil depletion'. These impact categories were mainly affected by indirect emissions from crude oil extraction/refining, which is the main energy source of the local grid, and from its combustion. For example, land is occupied during crude oil extraction and refining, while also access roads and other works for its extraction, its transportation to the refinery and then to the power plant are also needed, affecting thus the 'natural land transformation' impact category. Moreover, the extraction process and the construction of the petroleum refinery are associated to waste generation and disposal (e.g. organics and heavy metals), affecting the impact categories 'ecotoxicity' and 'eutrophication'. More specifically, according to Kelly, during diesel refining, arsenic emissions affect the 'human toxicity' category, while nitrogen oxides and sulfur dioxides emissions affect the 'marine eutrophication' and 'terrestrial acidification' categories, respectively. ${ }^{44}$ Also, oil combustion releases GHG emissions and other toxic emissions (e.g. polycyclic aromatic hydrocarbons (PAHs)), affecting the aforementioned impact categories; especially the 'ecotoxicity' and 'human toxicity' categories. The use of chemicals contributed mainly to 'marine, freshwater and human toxicity', 'terrestrial acidification', 'freshwater eutrophication' and 'particulate matter formation', having, however, a significantly lower score compared with the electricity consumption. These impacts were attributed to the facts that: (i) for the production of these chemicals both natural resources and energy were used, while also waterborne and airborne emissions are produced; and (ii) the use of these chemicals during solar Fenton oxidation resulted in direct waterborne emissions, especially when these chemicals were in excess. Moreover, the CPCs of the solar pilot plant were found to mainly contribute to the categories 'natural land transformation', 'marine ecotoxicity', 'freshwater ecotoxicity', 'freshwater eutrophication' and 'human toxicity' due to their manufacturing procedure, which is also energy intensive. Finally, the land that was occupied by the pilot plant caused the highest impact on the category 'urban land occupation', as expected.

It should be highlighted that comparison of the results of different LCA studies cannot be direct. This is because each study has different goals and scope definition, different equipment and impact assessment methods are used, the assumptions made are not fully equivalent, while also the energy mix and the geographical location of each study are different. ${ }^{40}$ However, according to the results of the study by Muñoz et al., the main environmental impact categories of the photo-Fenton process at bench scale for the treatment of kraft mill bleaching wastewater were the 'aquatic ecotoxicity', followed by the 'photochemical ozone formation', 'abiotic resource depletion' and 'acidification'. ${ }^{19}$ In addition, in the study by Serra et al., the major environmental impacts of the photo-Fenton process for the treatment of aqueous solutions polluted with non-biodegradable $\alpha$-MPG, were the 'human toxicity', 'freshwater aquatic ecotoxicity', 'ozone depletion' and 'abiotic resource depletion.45 According to the above, some of the main environmental impacts resulting from operation of the photo-Fenton process are the various types of ecotoxicity (i.e. human, marine and freshwater aquatic), a fact that is also in line with the results of this study, where solar Fenton oxidation at pilot scale was applied. However, in this study, the midpoint impact category 'natural land transformation' has the highest normalized score. The reason is twofold: (i) the high percentage of oil in the electricity mix used (i.e. land is occupied for its extraction, transportation and refinery and for construction purposes, such as roads and infrastructure); and (ii) the average annual impact per European citizen in this impact category is very low and therefore its normalized score is very high. ${ }^{44}$ In contrast, other impact categories have lower normalized scores, due to the fact that European citizens have 


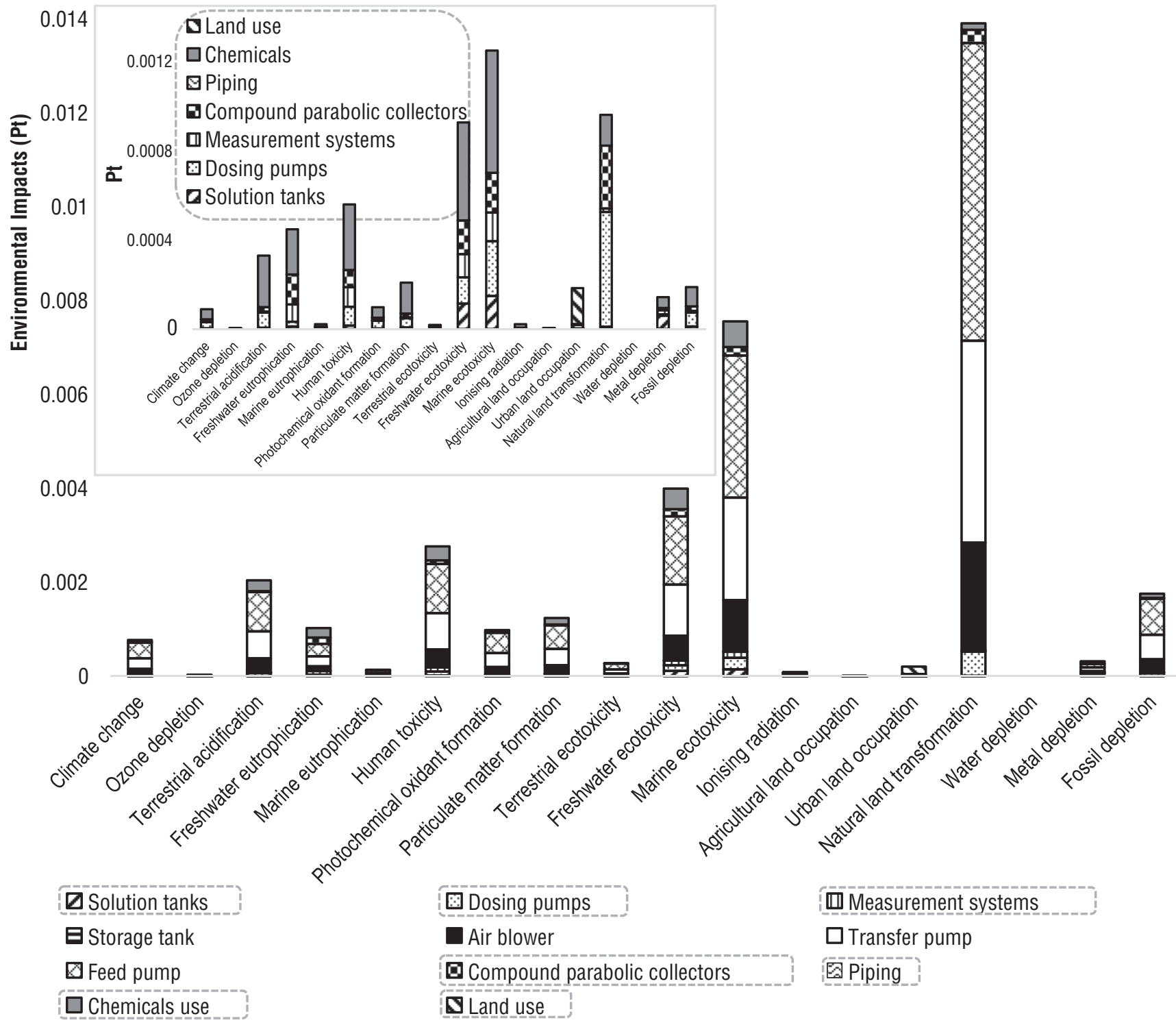

Figure 3. ReCiPe's normalized results for the treatment of $1 \mathrm{~m}^{3}$ of urban wastewater.

already very high annual impacts, such as the case of 'fossil fuel depletion'.

Summarizing the main findings of this study at midpoint level, the solar Fenton treatment of urban effluents mainly influenced the impact categories 'natural land transformation' and 'ecotoxicity', followed by 'terrestrial acidification' and 'fossil depletion'. These scores are traced back to oil consumption, and the associated extraction, transportation and refining procedures. Therefore, apart from airborne emissions (e.g. PAHs, COx, NOx and heavy metals) from oil combustion, which depending on the distance of the electricity power plant may or may not affect the local environment, the remaining categories are associated with indirect impacts that do not affect the local environment. Therefore, the only direct pressures on the local environment are attributed to the use of chemicals for the oxidation process, which results in corresponding waterborne emissions. However, these local pressures were a few orders of magnitude lower than the pressures from the indirect emissions (i.e. energy use), due to minimal amount of chemicals per treated $\mathrm{m}^{3}$ of wastewater. In addition, it should be highlighted that the optimum amounts of reagents were used in this study, and thus limited excess of chemicals was observed after the end of the treatment, minimizing further their potential impact. Moreover, the fact that this treatment process was proved to significantly reduce the treated effluent's toxicity towards both D. magna and the three plant species examined, is of high significance for this LCA study, minimizing further its direct pressures to the 'toxicity' impact categories, tracing back to the effluent's acute toxicity.

In addition, the results of the solar pilot plant LCIA were also aggregated, using ReCiPe's three endpoint damage categories, namely 'human health', 'ecosystems' and 'resources'. Their score is expressed in Eco-Indicator points $(\mathrm{Pt})$, where $1000 \mathrm{Pt}$ are the yearly environmental load of an average European citizen (i.e. 2.74 Pt/citizen day). The total environmental load of the solar pilot plant for the treatment of $1 \mathrm{~m}^{3}$ of urban wastewater, was found to be equal to $0.82 \mathrm{Pt}$. More specifically, $89.5 \%(0.74 \mathrm{Pt})$ of this environmental damage was attributed to energy consumption, $6.5 \%$ to chemical usage (from which $0.7 \%$ is attributed to $\mathrm{H}_{2} \mathrm{O}_{2}$, $1.5 \%$ to $\mathrm{H}_{2} \mathrm{SO}_{4}, 3.2 \%$ to $\mathrm{NaOH}, 1.04 \%$ to their transportation, while $\mathrm{FeSO}_{4}$ had a minimal contribution), $1.4 \%$ to $\mathrm{CPCs}, 0.7 \%$ to the tanks 
that were used for chemical storing (recycling was not taken into account in this case), $0.55 \%$ to the electronics that were used in the control unit and $0.37 \%$ to the land use.

From all the above, this process can be considered as a sustainable technology for the efficient treatment of secondary-treated urban effluents. The reason is that even though the total environmental footprint is approximately one-third of the average daily environmental footprint of a European capita (i.e. 2.74 Pt/day), which is not negligible, nonetheless the complete degradation of antibiotic compounds, which are CECs, have multiple environmental benefits, which cannot yet be estimated through the LCA methodology. However, its environmental footprint can be further reduced by examining alternative scenarios dealing with its main hotspots. To conclude, the main environmental hotspots of solar Fenton process that were identified in this study, both by the IPCC and ReCiPe impact assessment method, were two: (i) the energy demands, which is by far the most crucial parameter that affects the overall sustainability; and (ii) the use of chemicals, having a much lower score, at about one order of magnitude lower. As a consequence, alternative scenarios focusing on these parameters should be studied, aiming at further enhancing of the overall environmental performance of this technology.

\section{Alternative scenarios and sensitivity analysis}

Three alternative scenarios were examined, namely: (i) the use of a renewable energy source (S1) (i.e. solar energy), instead of electricity from the local energy grid; (ii) the performance of solar Fenton experiments in the inherent $\mathrm{pH}$ of urban effluents (S2) (i.e. no extra addition of $\mathrm{H}_{2} \mathrm{SO}_{4}$ for $\mathrm{pH}$ adjustment to 3 prior to solar Fenton oxidation, and as a consequence no extra addition of $\mathrm{NaOH}$ for neutral $\mathrm{pH}$ adjustment before their disposal into the environment); and (iii) the combination of the above alternative scenarios (S3). It should be noted that in this LCA study, it was taken into consideration that when the solar Fenton oxidation was performed at the inherent $\mathrm{pH}$ of wastewater $(\mathrm{pH}=7.0)$ (scenario S2) and at the optimum operating conditions (i.e. $5 \mathrm{mg} \mathrm{L}^{-1} \mathrm{Fe}^{2+}$ and $75 \mathrm{mg} \mathrm{L}^{-1} \mathrm{H}_{2} \mathrm{O}_{2}$ ), the complete degradation of OFX and TMP was achieved within 300 min of treatment, which was longer than the time required under acidic $\mathrm{pH}$ (approx. $180 \mathrm{~min}$ ); while the DOC removal achieved was reduced from $21 \%$ to $12 \%$ under the neutral conditions. $^{29}$

Moreover, the results of the LCIA study indicated that the main contributor to the environmental footprint of our process was the electricity consumption from the local energy grid. Since, the electricity mix is country specific, the environmental footprint of this process could have significant differences between countries and between different energy sources. Therefore, a sensitivity analysis was conducted to determine how variations of the electricity mix, would affect the environmental footprint of the system. For this reason, its environmental footprint using three different energy mixes from countries that have quite similar solar potential with those of Cyprus (Grid 1), namely Greece (Grid 2), Italy (Grid 3) and Spain (Grid 4) was examined. The energy mixes were obtained from Ecoinvent 3 database. Moreover, the results were compared with those obtained in the first alternative scenario (S1), i.e. solar energy (Grid 5), which is an abundant renewable energy source in the Mediterranean basin.

\section{Alternative scenario 1: use of solar energy}

It is important to mention that, according to the results obtained from previous LCA studies, the solar energy scenario drastically reduces the environmental impacts of various AOPs. ${ }^{19,23}$ Specifically, according to the study by Muñoz et al., for most of the advanced chemical processes investigated in their work (i.e. heterogeneous photocatalysis with or without $\mathrm{H}_{2} \mathrm{O}_{2}$ and solar Fenton oxidation at bench scale), the environmental impacts were reduced by more than $90 \%$, by avoiding the use of electricity for the light source (i.e. UV lamps), which implies a considerable amount of resources consumed and pollutants emitted to air and water from electricity consumption. ${ }^{19}$ For this reason, the use of solar energy, not only as a light source but also as an energy source, in AOPs applications should be promoted.

Thus, the first alternative scenario (S1) that was examined was substitution of the local energy mix by an environmentally friendly and renewable energy source, namely solar energy. Solar energy was examined since it constitutes a feasible alternative for the operation of the process under Mediterranean climate conditions, where there is plenty of sunshine all year round. More specifically, it was assumed that the energy needs were covered $100 \%$ by solar energy originating from a photovoltaic (PV) system that was connected to the electrical grid.

According to the results of IPCC 2013 impact assessment method, huge savings on the total GHG emissions of the system were observed in scenario S1. Specifically, if solar energy were to be used to cover the energy demands of our system, then it would show that for the treatment of $1 \mathrm{~m}^{3}$ of urban wastewater, the GHG emissions will be $1.46 \mathrm{~kg} \mathrm{CO}_{2 \mathrm{eq}} \mathrm{m}^{-3}$ instead of $8.66 \mathrm{~kg} \mathrm{CO}_{2 \mathrm{eq}}$ $\mathrm{m}^{-3}$ when the plant operated using the local energy mix (i.e. $83 \%$ reduction), minimizing significantly the toxic pollutants emitted to air and water. In this case, electricity consumption accounted for $50.1 \%$, the use of chemicals for $34.9 \%$ and the CPCs for $7.51 \%$ of the total GHG emissions. As shown from the above percentage values, the role of the use of chemicals was upgraded, in terms of its importance in the total airborne emissions compared with the conventional scenario, as was expected, since the contribution of the energy consumption was significantly reduced.

When the ReCiPe impact assessment method was used, the same pattern as when the IPPC 2013 method was applied was observed, since the total environmental footprint of the unit was found to be $0.178 \mathrm{Pt}$ (i.e. $78 \%$ reduction compared with the conventional scenario). In this case, the electricity consumption accounted for $51.3 \%$, the use of chemicals for $29.6 \%$ and the CPCs for $6.36 \%$ of the total environmental footprint of the plant, upgrading again the role of chemicals in terms of their contribution to the total environmental footprint. At midpoint level, the categories that were mainly affected by operation of the unit were the 'marine ecotoxicity' and 'freshwater ecotoxicity', which were attributed to three main reasons: (i) the indirect emissions associated with the manufacturing procedure of the PV panels (i.e. heavy metals, SOx, NOx, particulate matter (PM), $\mathrm{CO}_{2}$, toxic gas and GHG emissions); (ii) the high amounts of fossil fuels that were used during the manufacturing of the PV; and (iii) the use of chemicals and their waterborne emissions during the oxidation process. However, it should be noted that these 'toxicity' impact categories exhibited a significantly lower score compared with the conventional scenario. The damage category 'human health' was mainly affected in this scenario (i.e. it was affected by the indirect emissions during the manufacturing of PV panels), followed by the 'resources' category (i.e. it was mainly affected by raw materials and fossil fuel consumption for the PV production), while the category 'ecosystems' was found to have the lowest contribution to the total environmental footprint (i.e. it was mainly affected by heavy metal emissions). However, it should be noted that these damage categories 
exhibited a significantly lower score compared with the conventional scenario, highlighting the enhancement of the environmental performance of this system with the use of a renewable energy as an energy source.

\section{Alternative scenario 2: minimizing the use of chemicals}

In the second alternative scenario (S2) the effect of minimizing the use of chemicals (i.e. using only $\mathrm{H}_{2} \mathrm{O}_{2}$ and $\mathrm{FeSO}_{4} \cdot 7 \mathrm{H}_{2} \mathrm{O}$ for the solar Fenton oxidation), by performing the oxidation process at the inherent $\mathrm{pH}$ of urban effluents (no adjustment of effluent $\mathrm{pH}$ ), on the sustainability of the process was examined. As mentioned before, when solar Fenton oxidation was performed without modifying the $\mathrm{pH}$ of the wastewater, longer treatment time was required for complete degradation of the antibiotic compounds under study, and reduced removal of the effluent organic load was achieved; which were taken into consideration in the investigation of the environmental impacts of this alternative scenario.

When the IPPC 2013 method was used, a small reduction (i.e. $6 \%$ ) in the total GHG emissions was observed. Specifically, the total GHG emissions for the treatment of $1 \mathrm{~m}^{3}$ of wastewater by solar Fenton oxidation were found to be $8.13 \mathrm{~kg} \mathrm{CO}_{2 \mathrm{eq}} \mathrm{m}^{-3}$ instead of $8.66 \mathrm{~kg} \mathrm{CO}_{2 \text { eq }} \mathrm{m}^{-3}$ in the conventional scenario. The chemical use contributed $1.11 \%$ of the total GHG emissions, with $\mathrm{H}_{2} \mathrm{O}_{2}$ use being responsible for $1.0 \%$ and $0.1 \%$ for its local transportation. Thus, the limitations in the use of chemicals resulted in the corresponding savings of $\mathrm{NaOH}$ and $\mathrm{H}_{2} \mathrm{SO}_{4}$ and in reduction of the $\mathrm{GHG}$ emissions of chemical transportation, since lower amounts of chemicals were transported in this case. Moreover, a small saving in the total GHG emissions was achieved by removal of the $\mathrm{H}_{2} \mathrm{SO}_{4}$ dosing pump from the system and the electricity that this pump was consuming.

Similarly, when the ReCiPe impact assessment method was used the total environmental footprint of scenario S2 was equal to $0.77 \mathrm{Pt}$, achieving thus c. $6.5 \%$ reduction compared with the conventional scenario; while no remarkable differences in the midpoint and endpoint impact categories was observed.

\section{Alternative scenario 3: use of solar energy and minimizing the use of chemicals}

The most environmentally friendly scenario, feasible under the local climate conditions, is the combination of the alternative scenarios S1 and S2, i.e. the use of solar energy and the minimization of chemical use (no adjustment of effluent $\mathrm{pH}$ ). This alternative scenario (S3) combines the environmental benefits of the previous two scenarios, achieving thus higher environmental sustainability.

The total GHG emissions of scenario S3 were found to be 1.03 $\mathrm{kg} \mathrm{CO}_{2 \text { eq }} \mathrm{m}^{-3}$ (i.e. $88 \%$ reduction from the conventional scenario) according to the IPPC method. The main contributor to total GHG emissions was once again the energy consumption, but in this case it amounted to $70.4 \%$ (i.e. $0.73 \mathrm{~kg} \mathrm{CO}_{2 \text { eq }} \mathrm{m}^{-3}$ ) of the total GHG emissions, instead of $91.6 \%$ (i.e. $7.9 \mathrm{~kg} \mathrm{CO}_{2 \text { eq }} \mathrm{m}^{-3}$ ) in the conventional scenario; and with a significantly lower score (approx. 10-fold lower). Moreover, $10.6 \%$ of the total $\mathrm{CO}_{2}$ emissions was attributed to the CPCs and $8.7 \%$ to consumption of chemicals.

The environmental impacts of S3 were also simulated by the ReCiPe method, both at mid- and endpoint level, which were found to be $0.133 \mathrm{Pt}$, significantly reduced (about $84 \%$ ) compared with the conventional scenario. Similarly to the alternative scenario S1, the midpoint indicators that contributed the most to the total environmental impacts were 'freshwater ecotoxicity' and 'marine ecotoxicity'. However, due to restriction on the use of chemicals, these impact categories exhibited a lower score than in the case of S1. Therefore, scenario S3 was found to be a feasible alternative that could boost the sustainability of this process and enable its application at industrial level, where economies of scale exist.

\section{Sensitivity analysis of solar Fenton oxidation}

A sensitivity analysis of the main environmental hotspot, i.e. the electricity consumption, was carried out. The effect of different energy mixes of various Mediterranean countries that exhibit, at least in some of their parts, similar sunlight conditions with Cyprus (Grid 1), namely Greece (Grid 2), Italy (Grid 3) and Spain (Grid 4), was examined. It was assumed that in these countries, and especially in their southern parts, solar Fenton oxidation at pilot scale is possible to achieve a quite similar treatment performance of urban effluents.

A comparison of the $\mathrm{CO}_{2}$ emissions of the system using the various energy mixes, as well as using solar energy (Grid 5), which is a viable alternative in these areas, is shown in Fig. 4. As noted above, when the unit operated with Grid 1, then its total GHG emissions were $8.66 \mathrm{~kg} \mathrm{CO}_{2 \mathrm{eq}} \mathrm{m}^{-3}$, while when operating with Grid 5 a reduction of about $83 \%$ was achieved (i.e. $1.46 \mathrm{~kg} \mathrm{CO}_{2 \text { eq }}$ $\mathrm{m}^{-3}$ ). When Grid 2 (i.e. $54 \%$ solid fuels (i.e. lignite), $11 \%$ crude oil, $17 \%$ natural gas and $18 \%$ renewable energy) was assessed, an increase in the total emissions was observed, which was attributed to the use of lignite in this mix, a less environmentally friendly choice than oil. ${ }^{46}$ Specifically, the total GHG emissions were found to be $10.5 \mathrm{CO}_{2 \text { eq }} \mathrm{m}^{-3}$, about $17.5 \%$ higher compared to Grid 1, with electricity use being responsible for $93.1 \%$, chemicals for $4.8 \%$ and the CPCs for $1.1 \%$ of the total GHG emissions. In the case of Grid 3 (i.e. $51 \%$ fossil fuels, $39 \%$ natural gas, $10 \%$ renewable energy), a decrease of about $25 \%$ on the total $\mathrm{CO}_{2}$ emissions was observed, since the unit emitted $6.5 \mathrm{~kg} \mathrm{CO}_{2 \mathrm{eq}} \mathrm{m}^{-3}$. In this case, the electricity was responsible for $88.8 \%$, the chemicals for $7.9 \%$ and the CPCs for $1.7 \%$ of the total GHG emissions; which is a quite similar pattern with the above energy mixes (i.e. Grids 1 and 2), with a slight enhancing of the contribution of the use of chemicals. Finally, when Grid 4 (60\% fossil fuels, $9 \%$ hydropower, 19\% nuclear, $12 \%$ renewables) was used, then the total GHG emissions were

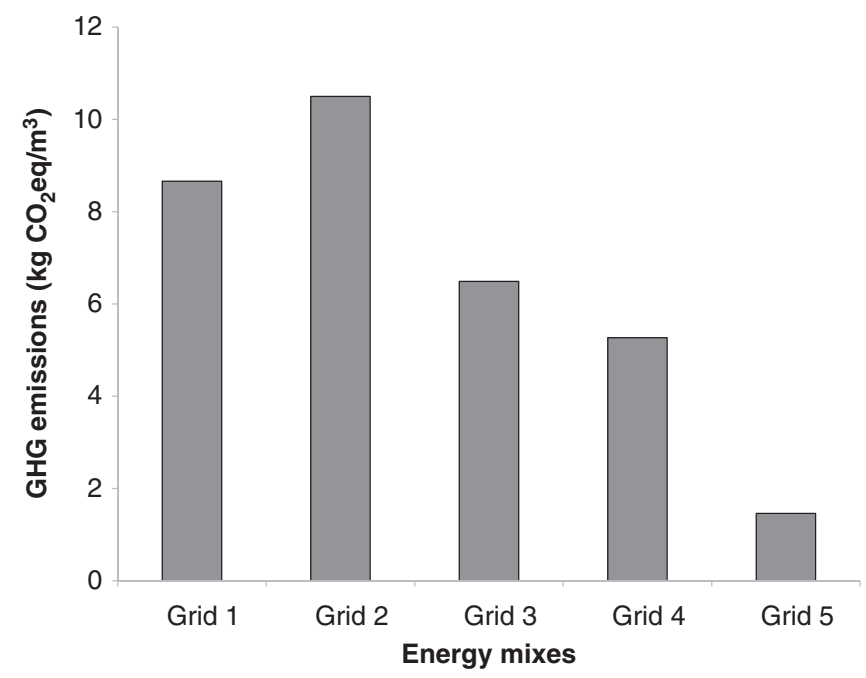

Figure 4. Total GHG emissions of solar Fenton oxidation for the different energy mixes of the Mediterranean countries examined. 
(a)

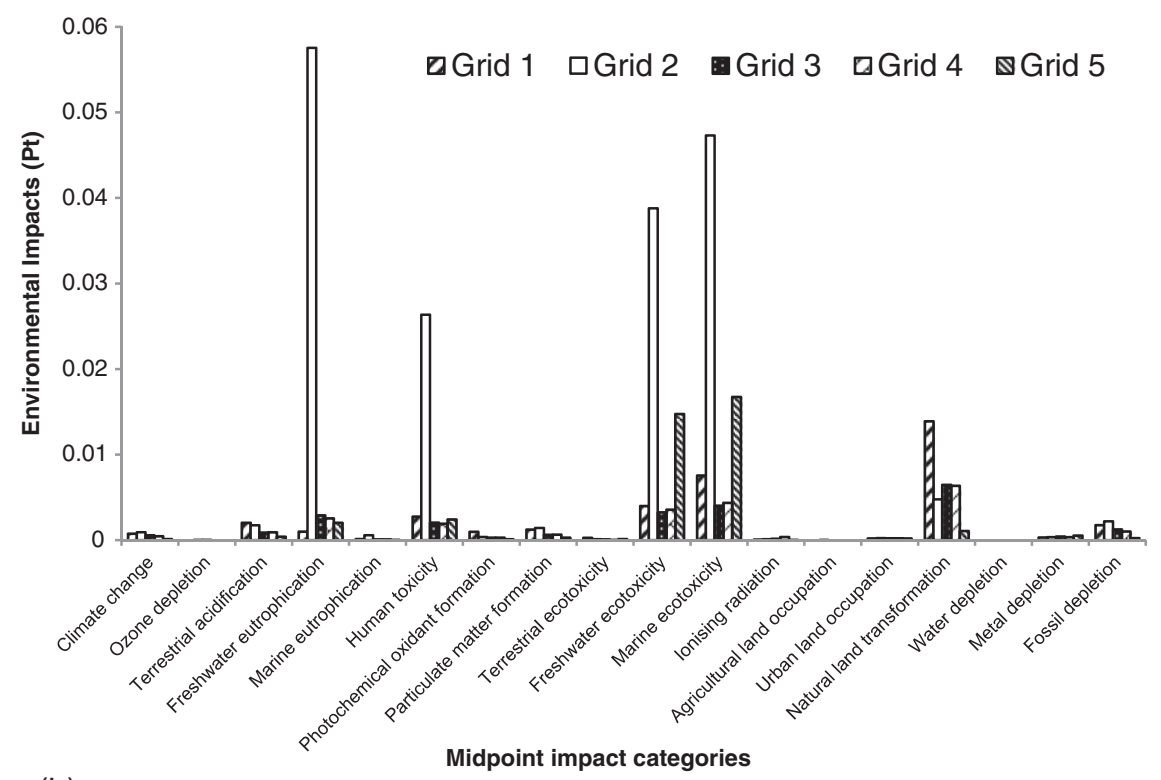

(b)

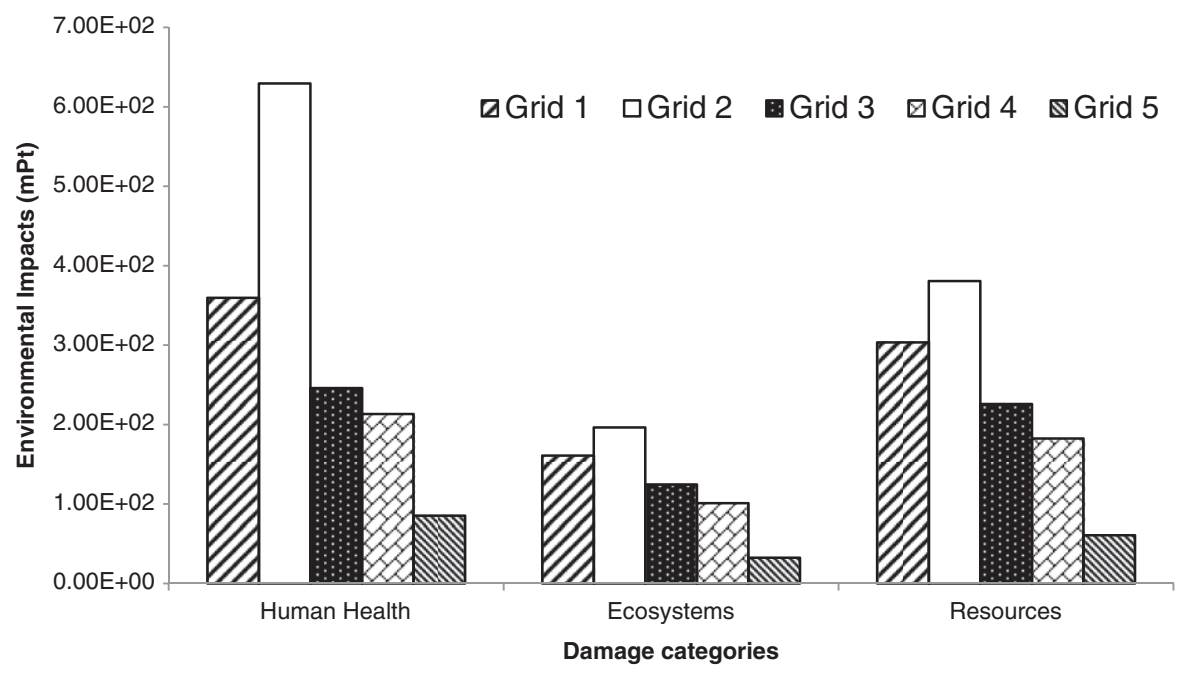

Figure 5. ReCiPe's (a) normalized midpoint impact categories, and (b) endpoint damage categories for the different energy mixes of the Mediterranean countries examined.

$5.3 \mathrm{~kg} \mathrm{CO}$ 2eq $\mathrm{m}^{-3}$, achieving thus the highest reduction of about $39 \%$ compared with Grid 1 . This reduction was mainly attributed to the high percentage of natural gas in the fossil fuel mix and the use of renewable energy sources in this mix (Grid 4). Electricity was found to be responsible for $86.2 \%$, while the contribution of chemicals use and CPCs was slightly enhanced up to $9.7 \%$ and $2.1 \%$, respectively. Thus, in all the energy mixes examined herein, energy consumption was found to be once again the main environmental hotspot, and the use of chemicals to be the second one, but with a lower score. As a consequence, it should be mentioned that the operational phase of the system (i.e. electricity and chemical use) was responsible for the majority of airborne emissions, with more than $90 \%$ contribution in all the cases examined herein.

ReCiPe results, at midpoint and endpoint level, are presented in Fig. 5. As shown, each energy mix affects a different impact category, with the case of Grid 5 being the most environmentally friendly scenario and Grid 2 the least, since lignite, a non-environmentally friendly resource is used. The impact categories were mainly affected by indirect emissions from the procedure of electricity generation, thus the differences in the energy mixes were reflected in different scores on each impact category. As observed, in all examined cases the damage category that exhibited the highest contribution was 'human health', closely followed by the damage category 'resources'. This was attributed mainly to indirect emissions from the electricity production of the different energy mixes used, and from the production and transportation of chemicals, ${ }^{47}$ while the direct waterborne emissions from the usage of chemicals affected mainly the damage categories 'human health' and 'ecosystem'.

\section{CONCLUSIONS AND OUTLOOK}

From the results obtained in the present study the environmental footprint of solar Fenton pilot plant for the treatment of $1 \mathrm{~m}^{3}$ of secondary-treated urban wastewater and for the mineralization of 
the two antibiotic compounds, when using the local energy grid, corresponds to the one-third of the daily environmental load of a European citizen or $1.6 \%$ of the GHG emissions emitted for the treatment of the daily wastewater effluents of a local resident. Even though this environmental footprint is not negligible, considering that this will be added in the environmental footprint of a conventional biological treatment, since solar Fenton oxidation will be applied as a tertiary treatment process, the mineralization of the selected antibiotic compounds from urban effluents has multiple environmental benefits in human health and ecosystems, which cannot yet be quantified by the LCA methodology. It can be concluded that the main contributor to the environmental load of the operation of this system is the indirect emissions from the electricity generation, followed by the direct/indirect emissions from the chemicals' used for the solar Fenton oxidation, with a significantly lower score. The most critical improvement identified in this study, is the diversification of the energy mix (i.e. use of a renewable energy source), which was proved to be the most sustainable choice; while the limitation of the chemicals use (i.e. avoiding $\mathrm{pH}$ adjustment) could also slightly improve its overall sustainability. Moreover, it was concluded that the environmental footprint of this treatment process is strongly related to the type of energy mix that is used, and as a consequence, when it operates using an energy mix which is based on a high extent on renewable energy sources, a significant enhancement of the overall environmental performance is observed.

\section{ACKNOWLEDGEMENTS}

This work was funded by Nireas, International Water Research Center of the University of Cyprus (NEA YПО $\Delta$ OMH/ 2 TPATH/0308/09), which was co-funded by the European Regional Development Fund and the Republic of Cyprus through the Research Promotion Foundation. The authors are grateful to the manufacturer company of the solar pilot plant, S.K. Euromarket Ltd, for providing technical support.

\section{FUNDING INFORMATION}

Nireas, International Water Research Center of the University of

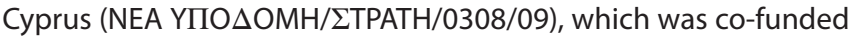
by the European Regional Development Fund and the Republic of Cyprus through the Research Promotion Foundation

\section{REFERENCES}

1 Maeng SK, Choi BG, Lee KT and Song KG, Influences of solid retention time, nitrification and microbial activity on the attenuation of pharmaceuticals and estrogens in membrane bioreactors. Water Res 47:3151-3162 (2013).

2 Michael I, Rizzo L, McArdell C, Manaia C, Merlin C, Schwartz T et al., Urban wastewater treatment plants as hotspots for the release of antibiotics in the environment: a review. Water Res 47:957-995 (2013).

3 Błędzka D, Gromadzińska J and Wąsowicz W, Parabens. From environmental studies to human health. Environ Int 67:27-42 (2014).

4 Michael-Kordatou I, Andreou R, lacovou M, Frontistis Z, Hapeshi E, Michael $C$ et al., On the capacity of ozonation to remove antimicrobial compounds, resistant bacteria and toxicity from urban wastewater effluents. J Hazard Mater doi:10.1016/j.jhazmat.2016.02.023 (2016).

5 Ternes TA, Joss A and Siegrist H, Scrutinizing pharmaceuticals and personal care products in wastewater treatment. Environ Sci Technol 38:393-399 (2004).
6 Radjenović J, Petrović M and Barceló D, Fate and distribution of pharmaceuticals in wastewater and sewage sludge of the conventional activated sludge (CAS) and advanced membrane bioreactor (MBR) treatment. Water Res 43:831-841 (2009).

7 Jelic A, Gros M, Ginebreda A, Cespedes-Sánchez R, Ventura F, Petrovic $M$ et al., Occurrence, partition and removal of pharmaceuticals in sewage water and sludge during wastewater treatment. Water Res 45:1165-1176 (2011).

8 EU, 2015/495. [Online]. Commission Implementing Decision Establishing a Watch List of Substances for Union-wide Monitoring in the Field of Water Policy Pursuant to Directive 2008/105/EC of the European Parliament and of the Council, Available: http://eur-lex.europa.eu/ legal-content/EN/TXT/PDF/? uri $1 / 4$ CELEX:32015D0495\&from $1 / 4$ EN [12 december 2015].

9 Huber MM, Canonica S, Park GY and von Gunten U, Oxidation of pharmaceuticals during ozonation and advanced oxidation processes. Environ Sci Technol 37:1016-1024 (2003).

10 Buffle MO, Schumacher J, Salhi E, Jekel M and von Gunten U, Measurement of the initial phase of ozone decomposition in water and wastewater by means of a continuous quench-flow system: application to disinfection and pharmaceutical oxidation. Water Res 40:1884-1894 (2006).

11 Klavarioti M, Mantzavinos D and Kassinos D, Removal of residual pharmaceuticals from aqueous systems by advanced oxidation processes. Environ Int 35:402-417 (2009).

12 Ioannou LA, Hapeshi E, Vasquez MI, Mantzavinos D and Fatta-Kassinos D, Solar $/ \mathrm{TiO}_{2}$ photocatalytic decomposition of $\beta$-blockers atenolol and propanolol in water and wastewater. Solar Energy 85:1915-1926 (2011).

13 Hapeshi E, Fotiou I and Fatta-Kassinos D, Sonophotocatalytic treatment of ofloxacin in secondary treated effluent and elucidation of its transformation products. J Chem Eng 224:96-105 (2013).

14 Michael-Kordatou I, lacovou M, Frontistis Z, Hapeshi E, Dionysiou DD and Fatta- Kassinos D, Erythromycin oxidation and ERY-resistant E. coli inactivation in urban wastewater by sulfate radical-based oxidation process under UV-C irradiation. Water Res 85:346-358 (2015).

15 Bauer $\mathrm{R}$ and Fallmann $\mathrm{H}$, The photo-Fenton oxidation - a cheap and efficient wastewater treatment method. Res Chem Intermed 23:341 - 354 (1997).

16 Rebitzer G, Ekvall T, Frischknecht R, Hunkeler D, Norris G, Rydberg T et al., Life cycle assessment Part 1: framework, goal and scope definition, inventory analysis, and applications. Environ Int 30:701-720 (2004).

17 Sala $L$ and Serra M, Towards sustainability in water recycling. Water Sci Technol 50:1 -7 (2004).

18 Corominas L, Foley J, Guest JS, Hospido A, Larsen HF, Morera S et al., Life cycle assessment applied to wastewater treatment: state of the art. Water Res 47:5480-5492 (2013).

19 Muñoz I, Rieradevall J, Torrades F, Peral J and Domenech X, Environmental assessment of different solar driven advanced oxidation processes. Solar Energy 79:369-375 (2005).

20 Muñoz I, Rieradevall J, Torrades F, Peral J and Domenech X, Environmental assessment of different advanced oxidation processes applied to a bleaching Kraft mill effluent. Chemosphere 62:9-16 (2006a).

21 Meneses M, Pasqualino JC and Castells F, Environmental assessment of urban wastewater reuse: Treatment alternatives and applications. Chemosphere 81:266-272 (2010).

22 Chatzisymeon E, Foteinis S, Mantzavinos D and Tsoutsos T, Life cycle assessment of advanced oxidation processes for olive mill wastewater treatment. J Clean Prod 54:229-234 (2013).

23 Muñoz I, Perala J, Ayllona JA, Malato S, Passarinho P and Domenech X, Life cycle assessment of a coupled solar photocatalytic-biological process for wastewater treatment. Water Res 40:3533-3540 (2006b).

24 Farré MJ, García-Montaño J, Ruiz N, Muñoz I, Domènech X and Peral $J$, Life cycle assessment of the removal of diuron and linuron herbicides from water using three environmentally friendly technologies. Environ Technol 28:819-830 (2007).

25 Muñoz I, Rodríguez A, Rosal R and Fernández-Alba AR, Life cycle assessment of urban wastewater reuse with ozonation as tertiary treatment. A focus on toxicity-related impacts. Sci Total Environ 407:1245-1256 (2009). 
26 Serra A, Domenech X, Brillas E and Peral J, Life cycle assessment of solar photo-Fenton and solar photoelectro-Fenton processes used for the degradation of aqueous a-methylphenylglycine. J Environ Monitor 13:167-174 (2011a).

27 Giménez J, Bayarri B, González Ó, Malato S, Peral J and Esplugas S, Advanced oxidation processes at laboratory scale: environmental and economic impacts. ACS Sustainable Chem Eng 3:3188-3196 (2015).

28 Rodríguez R, Espada JJ, Pariente MI, Melero JA, Martínez F and Molina R, Comparative life cycle assessment (LCA) study of heterogeneous and homogenous Fenton processes for the treatment of pharmaceutical wastewater. J Clean Prod 124:21-29 (2016).

29 Michael I, Hapeshi E, Michael C, Varela AR, Kyriakou S, Manaia C et al., Effectiveness of solar Fenton process on abatement of antibiotics at a pilot plant scale: degradation kinetics, ecotoxicity assessment and removal of antibiotic resistant enterococci. Water Res 46:5621-5634 (2012).

30 loannou LA, Michael C, Kyriakou S and Fatta-Kassinos D, Solar Fenton: from pilot to industrial scale application for polishing winery wastewater pretreated by MBR. J Chem Technol Biotechol 89:1067-1076 (2014)

31 Cyprus Regulatory Administrative Act on the pollution of water bodies (urban wastewaters discharges), 2003/772, (2003).

32 Hoffmann E and Homa J, Carbon footprint and LCA study for different coagulants produced from INCOPA member companies. INCOPA General Assembly. Berlin, 16.09.2011, (2011).

33 ABB, (2015). [Online]. ASEA Brown Boveri, Available: http://www.abb .com/ [15 May 2015].

34 Sand $M$, Factors affecting lifetime costs of water supply pipelines. Proceeding in: Institute of Municipal Engineering of South Africa (IMESA) conference 2013 South Africa (2013).

35 European Environment Agency (EEA), Life Cycle Assessment (LCA), A guide to approaches, experiences and information sources (1997).

36 Electricity Authority of Cyprus, (2015). [Online]. Available: http://www. dsm.org.cy/media/attachments/RES/RES_PENETRATION_20122013.pdf [10 June 2015]
37 Environmental Product Declaration, (2006). [Online]. Electric Motor Type 9054 Pole (3GAA092001-ASC), ABB Motors A/S, Petersmindevej 1, DK-5000 Odense C. Available: http://www.dantes.info/ Publications/Publications-info/ABB_EPD_90S-4Pole.html [5 June 2016].

38 DANTES, (2015). [Online]. Available: http://www.dantes.info/ Publications/Publications-info/ABB_EPD_90S-4Pole.html March 2015].

39 EPD, (2012). Climate Declaration for pump MINEX 8101.171. [Online]. Available: http://gryphon.environdec.com/data/files/6/9480/ cd164.pdf [15 March 2016].

40 Ioannou-Ttofa L, Foteinis S, Chatzisymeon E and Fatta-Kassinos D, The environmental footprint of a membrane bioreactor treatment process through Life Cycle Analysis. Sci Total Environ 568:306-318 (2016).

41 Malato S, Fernández-Ibáñez P, Maldonado M, Blanco J and Gernjak W, Decontamination and disinfection of water by solar photocatalysis: recent overview and trends. Catal Today 147:1-59 (2009).

42 European Environmental Agency (EEA), [Online]. Country profile - Cyprus, (2014). Available: http://www.eea.europa.eu/soer/ countries/cy/country-introduction-cyprus-2 [May 2015].

43 AQUASTAT, (2013). [Online]. Available: http://www.fao.org/nr/water/ aquastat/data/query/results.html [20 May 2015].

44 Kelly KA, An Environmental Life Cycle Assessment of Energy Systems Leading to a Pathway for a Low Carbon Economy (Doctoral dissertation, University of Bath), (2013).

45 Serra $A$, Brillas $E$, Domènech $X$ and Peral J, Treatment of biorecalcitrant a-methylphenylglycine aqueous solutions with a solar photo-Fenton-aerobic biological coupling: biodegradability and environmental impact assessment. J Chem Eng 172:654-664 (2011b).

46 Theodosiou G, Koroneos C and Stylos N, Environmental impacts of the Greek electricity generation sector. Sustain. Energy Technol Assess 5:19-27 (2014).

47 Foteinis $\mathrm{S}$ and Chatzisymeon $\mathrm{E}$, Life cycle assessment of organic versus conventional agriculture. A case study of lettuce cultivation in Greece. J Clean Prod 112:2462-2471 (2016). 